\title{
ANÁLISE DE FALTAS COM BARREIRA EM JOGOS DE FUTSAL FEMININO DE ALTO RENDIMENTO
}

\author{
Wilton Carlos Santana \\ Universidade Estadual de Londrina, Londrina, Paraná, Brasil \\ Edcarlos Aparecido Vacario \\ Universidade Estadual de Londrina, Londrina, Paraná, Brasil
}

\begin{abstract}
Resumo
Este artigo objetiva analisar ações ofensivas de faltas com barreira em jogos de futsal feminino de alto rendimento. Foi levantada a efetividade de gols e a localização de faltas em distintas zonas da quadra ofensiva. Observaram-se $89(5,93 \pm 3,08)$ ações, retiradas de 15 jogos da Taça Brasil de Clubes. Encontrou-se efetividade de $5,62 \%$; tendência defensiva de se evitar faltas centrais e próximas da meta; maior parte dos gols originados de faltas centrais; igualmente, maior efetividade de tentos originados dessas situações do que de faltas laterais e; leve superioridade na efetividade de gols de faltas de meia distância em comparação à de faltas próximas. Concluiu-se que é preciso aumentar a eficácia em faltas com barreira, sobretudo em zonas laterais.
\end{abstract}

Palavras-chave: Futsal. Tática. Análise de Jogo. Gênero Feminino.

\section{Introdução}

$\mathrm{O}$ futsal feminino é uma modalidade que desde o início da década passada tem recebido mais atenção da Confederação Brasileira de Futsal (CBFS). Ratifica essa afirmação, entre outros aspectos, a formação de uma seleção brasileira permanente e o advento de campeonatos expressivos, como o Brasileiro de Seleções, a Liga Futsal e o Sul-Americano de Seleções (SANTANA; REIS, 2003; SANTANA, 2007).

Se por um lado a modalidade parece viver seu mais bem-sucedido momento histórico, por outro carece de estudos que retratem aspectos da sua lógica interna tático-técnica, isto é, peculiaridades presentes nas distintas fases do jogo (ataque, defesa e respectivas transições) (HERNÁNDEZ MORENO, 1999). 
Isso se constitui numa lacuna, pois o levantamento de aspectos tático-técnicos do jogo, manifestados no comportamento dos jogadores em situação de competição, ajudaria os treinadores a compreenderem a tendência evolutiva dos esportes, o que os auxiliaria quando da preparação de suas equipes para o treino e a competição. A fim de retratar a lógica tático-técnica, os pesquisadores têm utilizado a ferramenta da análise de jogo (GARGANTA, 2001; TAVARES, 2002, 2006).

Em se tratando de futsal, um esporte de cooperação-oposição, jogado num espaço comum e com a participação simultânea dos jogadores sobre a bola (HERNÁNDEZ MORENO, 1998), é possível investigar aspectos tático-técnicos variados dessa lógica, pois a ação de jogo resulta da interação entre os jogadores, ora envolvidos com a manutenção da posse da bola, ora envolvidos com a sua recuperação (SAMPEDRO, 1999).

Diante dessa diversidade tático-técnica situacional, optou-se neste estudo pela observação de situações de bola parada, muito frequentes em partidas de futsal de alto rendimento (JACHETA, 2009) e relatadas por técnicos de alto rendimento da modalidade como primordiais para que o ataque como um todo seja eficaz (SANTANA, 2008). Em particular, a análise incidiu sobre as faltas com formação de barreira na meia quadra ofensiva.

As faltas se encaixam no plano estratégico da equipe, pois permitem que os treinadores, de antemão, tracem planos para confundir a defesa adversária (VALDERICEDA, 1994; LOZANO CID, 1995; CHAVES CHAVES; RAMÍREZ AMOR, 1998; VELASCO TEJADA; LORENTE PEÑAS, 2003; SILVA; CALADO FILHO, 2005). Por isso, são acompanhadas de grande expectativa quando se trata da conversão de gols, embora se saiba que as finalizações oriundas dessas situações representam uma baixa percentagem do total de finalizações de uma equipe profissional (JACHETA, 2009).

Se por um lado esses indícios, por si só, justificariam sessões de treinamento específicas para essas situações (SAAD; COSTA, 2001; SANTANA, 2004), por outro se nota uma escassez de estudos sobre o tema. Sendo assim, o propósito deste estudo foi analisar ações ofensivas de faltas com barreira em jogos de futsal feminino de alto rendimento, apontando a sua frequência em distintas zonas da quadra ofensiva e respectivas efetividades de gols (aproveitamento). 


\section{Metodologia}

Tipo de estudo

Trata-se de um estudo quantitativo, do tipo descritivo observacional (GAYA, 2008).

Amostra

Foram observadas $89(5,93 \pm 3,08)$ ações ofensivas que se iniciaram com a bola parada em situações de falta localizadas na meia quadra ofensiva e que permitiram a formação de barreira. Portanto, foram excluídos os pênaltis e os tiros livres dos 10 metros. A amostra foi retirada de 15 partidas da fase final da $18^{\text {a }}$ Taça Brasil de Clubes 2009 e corresponde a $100 \%$ do total dessas ações nesses jogos.

Coleta de dados

Os pesquisadores observaram os jogos em mídia DVD e selecionaram as cenas que continham faltas com formação de barreira na meia quadra ofensiva. Posteriormente, as ações foram registradas, por estimativa visual, em um campograma (Figura 1), no qual a meia quadra ofensiva foi subdividida em nove zonas: Z1 (ala direita, próxima da meta), Z2 (ala direita, meia distância da meta), Z3 (ala direita, longe da meta), Z4 (centro, próxima da meta), Z5 (centro, meia distância da meta), Z6 (centro, longe da meta), Z7 (ala esquerda, próxima da meta), Z8 (ala esquerda, meia distância da meta) e Z9 (ala esquerda, longe da meta). 


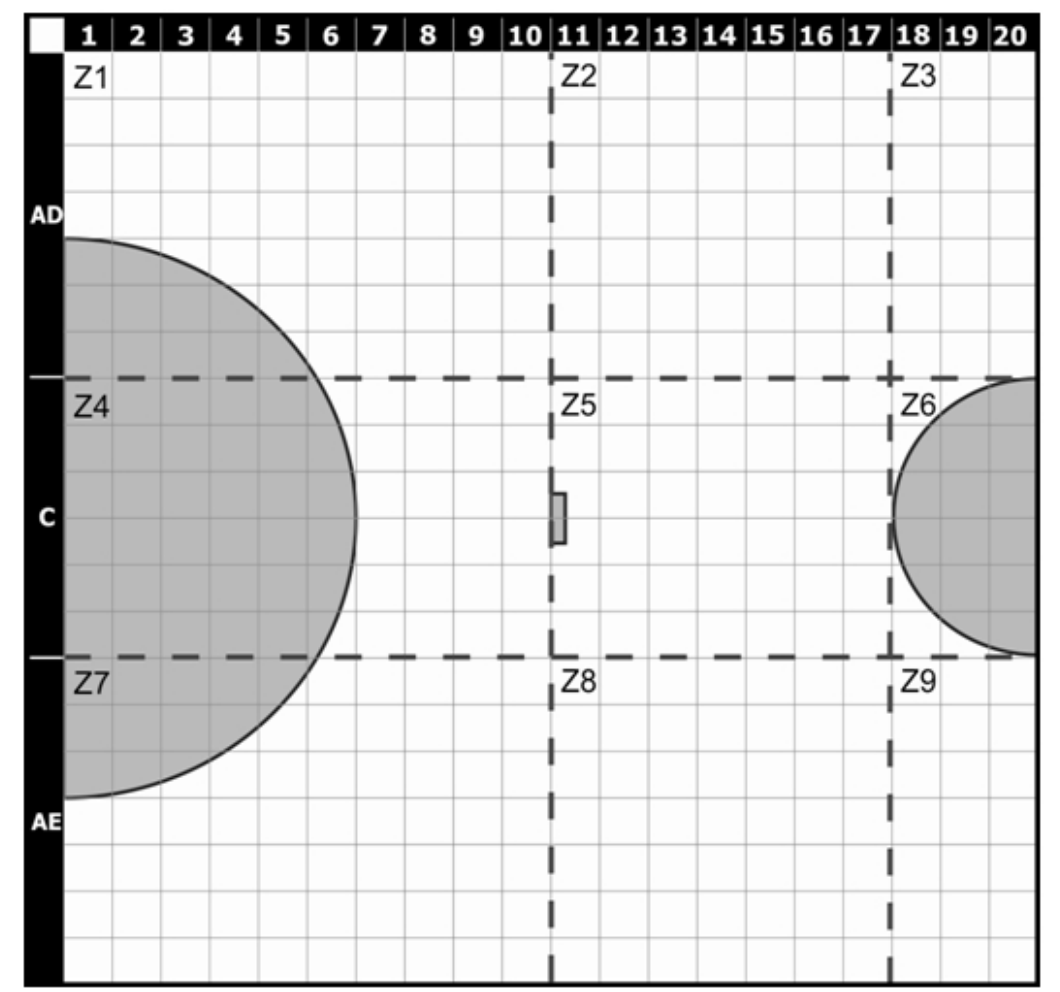

Figura 1: Campograma para notação das faltas com barreira na meia quadra ofensiva

Análise estatística

Foram adotadas estatísticas descritivas (média e desvio-padrão) e valores de frequência absoluta $(\mathrm{F})$ e relativa $(\%)$.

\section{Resultados e discussão}

A Tabela 1 contempla a frequência absoluta e relativa de faltas com barreira em diferentes zonas da quadra; identifica as respectivas distâncias da meta; aponta os gols convertidos e a efetividade destes em cada zona particular. 
Tabela 1: Frequência absoluta e relativa de faltas em diferentes zonas da quadra e gols convertidos

\begin{tabular}{|c|c|c|c|c|c|}
\hline $\begin{array}{l}\text { Zonas } \\
\text { da quadra }\end{array}$ & $\begin{array}{l}\text { Distância } \\
\text { da meta }\end{array}$ & $\mathrm{F}$ & $\%$ & Gols & Efetividade \\
\hline Z1 (ala direita) & Próxima & 12 & 13,48 & 1 & 8,33 \\
\hline Z2 (ala direita) & Meia distância & 21 & 23,59 & 0 & 0 \\
\hline Z3 (ala direita) & Longe & 9 & 10,11 & 0 & 0 \\
\hline Z4 (centro) & Próxima & 7 & 7,86 & 1 & 14,28 \\
\hline Z5 (centro) & Meia distância & & 5,61 & 2 & 40 \\
\hline Z6 (centro) & Longe & 2 & 2,24 & 0 & 0 \\
\hline Z7 (ala esquerda) & Próxima & 13 & 14,6 & 0 & 0 \\
\hline Z8 (ala esquerda) & Meia distância & 15 & 16,85 & 1 & 6,66 \\
\hline Z9 (ala esquerda) & Longe & 5 & 5,61 & 0 & 0 \\
\hline Total & & 89 & 100 & 5 & \\
\hline Média/DP & & $5,93 \pm 3,08$ & & $0,83 \pm 0,75$ & \\
\hline Efetividade & & $5,6 \%$ & & & \\
\hline
\end{tabular}

Considerando-se o número de gols marcados em todas as zonas, verifica-se um total de 5 tentos, o que corresponde à efetividade de $5,62 \%$. Esse achado corrobora o estudo de Pessoa et al. (2009), que analisaram 20 jogos da $1^{\text {a }}$ fase da Liga Futsal 2009 (masculina) e encontraram a efetividade de gols de faltas de 6,8\%; também, em parte, o de Silva et al. (2004), que ao analisar 4 jogos da seleção brasileira sub-20 em um torneio internacional diagnosticaram que de um total de 156 finalizações a gol, 21 foram provenientes de situações de bola parada (não apenas de faltas), sendo a efetividade nesses casos de 4,76\%. Em contrapartida, o resultado diverge do encontrado por Jacheta (2009), que analisou sequências ofensivas iniciadas por falta da seleção brasileira em 5 jogos da Copa do Mundo de Futsal 2008 e detectou a efetividade de $13,33 \%$. Reporte-se que nesse estudo a amostra apresentou jogos do Brasil contra seleções de níveis muito heterogêneos, como por exemplo, Cuba, Ilhas Salomão (que não passaram da $1^{\text {a }}$ fase), Ucrânia, Irã (que não passaram da $2^{\mathrm{a}}$ fase) e Itália (semifinalista).

Ao se comparar a efetividade de gols marcados considerando as regiões centrais (Z4, Z5 e Z6) e as laterais (Z1, Z2, Z3, Z7, Z8, Z9), encontra-se o valor de $21,42 \%$ para o primeiro caso e $2,66 \%$ para o segundo. Esse achado sugere que a defesa deveria evitar cometer faltas nas regiões centrais, optando pelas laterais.

Notou-se, também, que a efetividade de gols de faltas de meia distância, considerando a região central $(Z 5)$ e as regiões laterais $(Z 2$ e 
$\mathrm{Z} 8$ ), foi maior do que a de faltas próximas (Z1, Z4 e Z7), respectivamente, $7,31 \%$ e $6,25 \%$. Embora seja baixa a efetividade de gols nesses casos, a defesa ainda deveria evitá-las, sendo seguro somente cometer faltas distantes da meta (Z3, Z6 e Z9), pois não originaram gols.

A Figura 2 contempla, no geral, a localização das faltas com barreira na meia quadra ofensiva, respeitadas as distintas zonas; em particular, com destaque, mostra o local das faltas que originaram gols.

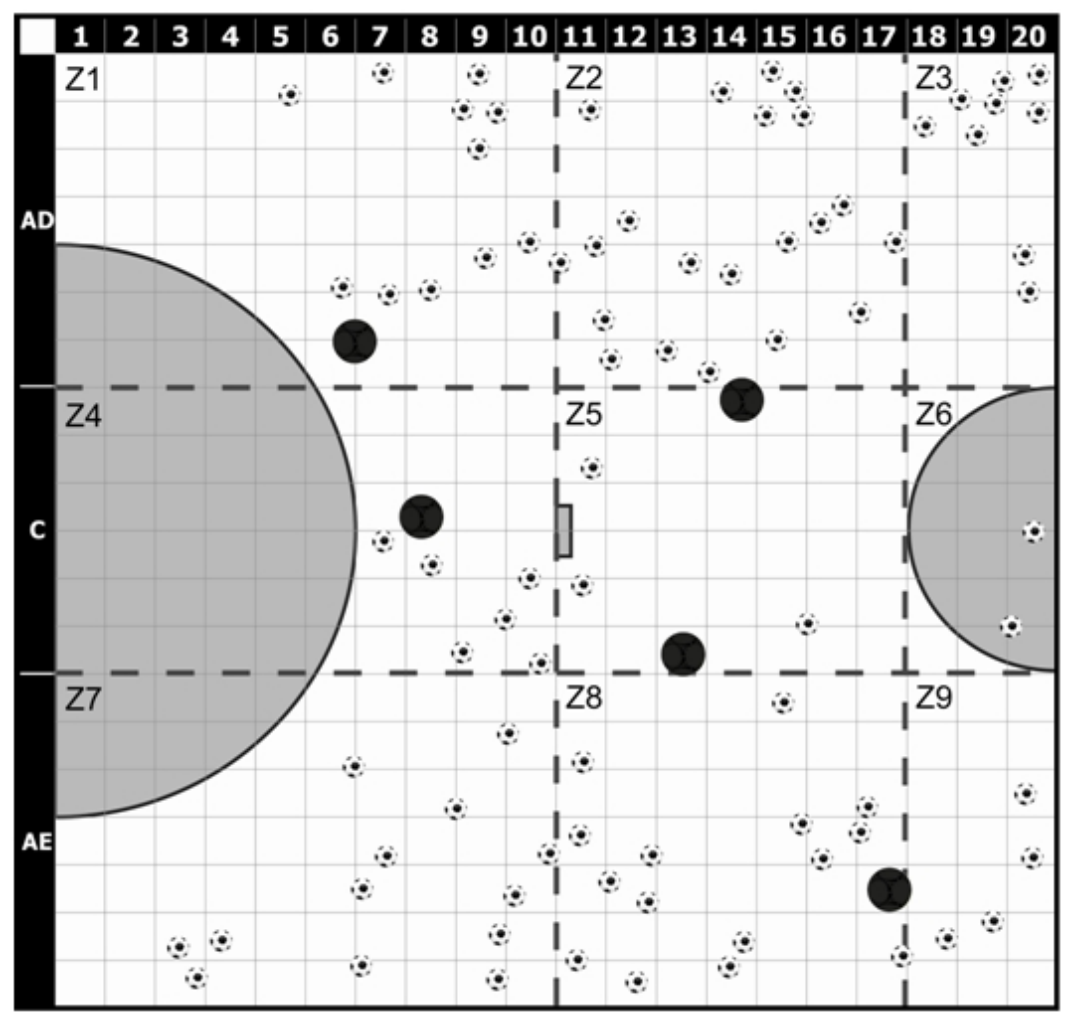

Figura 2: Localização das faltas no campograma

Verifica-se na figura que a maior parte das faltas está localizada em zonas laterais da quadra $(84,26 \%)$ e a menor parte em zonas centrais $(15,74 \%)$. Igualmente, considerando-se a somatória de faltas localizadas em distâncias médias e afastadas (longa), notam-se mais ações afastadas $(64,05 \%)$ do que próximas da meta $(35,95 \%)$. Portanto, configura-se uma tendência defensiva de se evitar faltas nas regiões centrais e próximas da meta, optando-se por zonas laterais e mais afastadas.

Não obstante tenha sido menor a frequência de faltas nas regiões centrais quando comparadas às situadas nas regiões laterais, verificase que $60 \%$ dos gols surgiram de faltas centralizadas. Isso pode ser ex- 
plicado pelo fato de as faltas nessas regiões, sejam próximas ou em meia distância, exigirem a colocação de mais jogadores na barreira, facultando ao ataque uma superioridade de jogadores nos setores de finalização. Isso, em tese, proporcionaria menor vantagem territorial à defesa e maiores dificuldades para esta interpretar as intenções do adversário e impedir o arremate contra a meta.

No entanto, dois fatores associados tendem a dificultar a consecução de tentos de faltas lateralizadas, as mais incidentes: o primeiro relacionado ao ataque e o segundo à defesa. No aspecto ofensivo, em virtude do menor ângulo de chute ao gol presente nessas situações, o ataque se vê obrigado a circular a bola para regiões centrais, de maior ângulo para o arremate. Entretanto, a defesa tem o privilégio de deslocar menos jogadores para a formação da barreira, o que lhe faculta a liberação de outros para ocupar possíveis espaços de finalização adversária. Por extensão, esse conjunto de fatores, em tese, tende a permitir à defesa maior vantagem territorial, além de ganhar mais tempo para interpretar as intenções ofensivas adversárias e evitar a finalização.

\section{Conclusão}

O estudo permite concluir e, simultaneamente, sugerir aos técnicos de futsal feminino de alto rendimento que: (i) faltas nas zonas centrais, com a exceção das distantes, deveriam ser sumariamente evitadas tanto quanto sistematicamente treinadas ofensivamente, pois proporcionaram mais gols e maior efetividade; (ii) a opção defensiva de fazer faltas nas zonas laterais é acertada, pois embora mais incidentes, geraram menos gols e menor efetividade; (iii) é preciso buscar maior eficácia ofensiva em faltas com barreira, qualificando as estratégias adotadas, pois há uma elevada incidência de ações, mas é baixa a efetividade de gols. Isso é ainda mais evidente para as faltas cobradas em zonas laterais da quadra.

Sugerem-se outros estudos acerca dessa variável tático-técnica, em particular um que verifique qual o tipo de comportamento ofensivo e defensivo adotado pelas equipes de futsal feminino nas cobranças de faltas com barreira. 


\title{
Analysis of fouls with hurdles in high lever female futsal
}

\begin{abstract}
This paper has the purpose to analyze offensive actions of fouls with hurdles in high level female futsal. It was verified the goals efficacy and site of fouls in distinctive zones in the offensive court. It was observed $89(5,93+3,08)$ actions, extracted from 15 futsal games of Brazil Clubs Championship. The results indicated an efficacy of 5,62\%; a deffensive trend related to avoid fouls in the center of the court and close to the goal positions; the greatest part of the goals came from the central fouls and greater efficacy of the goals occurred in these situations rather than in the lateral fouls; a greater efficacy was found in the goals originated of halfdistance fouls when compared to the fouls closer the goals. It was concluded that we need to increase the effectiveness of fouls with hurdles, especially in lateral areas.
\end{abstract}

Keywords: Futsal. Tactics. Game Analysis. Female Gender.

Análisis de faltas com barrera em juegos de fútebol sala femenino de alto rendimiento

\section{Resumen}

Este artículo tiene como objetivo analizar las acciones ofensivas faltas con barrera en juegos de fútbol sala femenino de alto rendimiento. Que ha planteado la eficacia de los goles y la ubicación de faltas en las diferentes áreas del campo ofensivo. Hay $89(5,93 \pm 3,08)$ acciones, tomadas de 15 partidos de la Copa Brasil Club. Se encontró con la eficacia de 5,62\%; una tendencia a la defensiva para evitar faltas centrais y cerca del portería central; que la mayoría de los goles de su origen en faltas centrales; y también aumentó la eficacia de los goles derivados de estas situaciones lado de las faltas y una ligera superioridad en la eficacia de goles de faltas en media distancia en comparación con la de faltas cercanas. Se concluyó que es necesario aumentar la eficacia de goles en faltas con barrera, especialmente en las zonas laterales.

Palabras clave: Fútbol Sala. Táctica. Análisis del Juego. El Género Femenino.

\section{Referências}

CHAVES CHAVES, J. L.; RAMÍREZ AMOR, J. A. Táctica y estratégia en fútbol sala: situaciones de ataque y defensa. Barcelona: Hispano Europea, 1998.

GARGANTA, J. A análise da performance nos jogos desportivos: revisão acerca da análise de jogo. Revista Portuguesa de Ciência do Desporto, v. 1, n. 1, p. 57-64, 2001.

GAYA, A. Desenhos metodológicos V: delineamentos do tipo ex post facto. In: GAYA, A. Ciências do movimento humano: introdução à 
metodologia da pesquisa. Porto Alegre: Artmed, 2008. p. 151-172.

HERNÁNDEZ MORENO, J. Fundamentos del deporte: análisis de las estructuras del juego deportivo. 2. ed. Barcelona: INDE, 1998.

HERNÁNDEZ MORENO, J. La diversidad de prácticas. Análisis de la estructura de los deportes para su aplicación a la iniciación deportiva. In: BLÁZQUEZ SANCHEZ, D. La iniciación deportiva y el deporte escolar. 4. ed. Barcelona: INDE, 1999. p. 287-310.

JACHETA, V. V. Análise das sequências ofensivas iniciadas por bola parada da seleção brasileira na Liga Mundial de Futsal de 2008. 2009. 54 f. Monografia (Bacharelado em Educação Física) - Faculdade de Educação Física, Universidade Estadual de Campinas, Campinas, 2009.

LOZANO CID, J. Futbol sala: experiências tácticas. Madrid: Real Federación Española de Fútbol, 1995.

PESSOA, V. L. et al. Análise dos gols da Liga Futsal 2008. Lecturas: Educación Física y Desportes, Revista Digital, ano 13, n. 129, p. 1, fev. 2009. Disponível em: <http://www.efdeportes.com/efd129/analise-dos-gols-da-liga-futsal-2008.htm>. Acesso em: 10 jul. 2011.

SAAD, M. A.; COSTA, C. F. Futsal: movimentações ofensivas e defensivas. Florianópolis: Bookstore, 2001.

SAMPEDRO, J. Fundamentos de táctica deportiva: análisis de la estrategia de los deportes. Madrid: Gymnos, 1999.

SANTANA, W. C. Futsal: apontamentos pedagógicos na iniciação e na especialização. Campinas: Autores Associados, 2004.

SANTANA, W. C. A expansão do futsal feminino. Pedagogia do Futsal, p. 1, abr. 2007. Disponível em: <http://www.pedagogiadofutsal.com.br/interna_editoriais.aspx?id=36>. Acesso em: 4 jul. 2011.

SANTANA, W. C. A visão estratégico-tática de técnicos campeões da Liga Nacional de Futsal. 2008. 260 f. Tese (Doutorado em Educação Física) - Faculdade de Educação Física, Universidade Estadual de Campinas,Campinas, 2008. 
SANTANA, W. C.; REIS, H. H. B. Futsal feminino: perfil e implicações pedagógicas. Revista Brasileira de Ciência e Movimento, v. 11, n. 4, p. 45-50, out./dez. 2003.

SILVA, M. et al. Ações ofensivas no futsal: uma comparação entre as situações de jogo organizado, de contra-ataque e de bola parada. Revista Portuguesa de Ciências do Desporto, ano 4, n. 2, p. 199. 2004. (Suplemento).

SILVA, R. A. M.; CALADO FILHO, C. M. Formación de entrenadores de futsal de máximo nivel: técnica y táctica. Espanha: Fifa, 2005.

TAVARES, F. Análise da estrutura e dinâmica do jogo nos jogos desportivos. In: BARBANTI, V. J. et al. Esporte e atividade física: interação entre rendimento e saúde. São Paulo: Manole, 2002. p.129-143.

TAVARES, F. Analisar o jogo nos esportes coletivos para melhorar a performance. Uma necessidade para o processo de treino. In: ROSE JUNIOR, D. Modalidades esportivas coletivas. Rio de Janeiro: Guanabara Koogan, 2006. p. 60-67.

VALDERICEDA, F. Futbol sala: defensa, ataque, estrategias. Madrid: Gymnos, 1994.

VELASCO TEJADA, J.; LORENTE PEÑAS, J. Entrenamiento de base en fútbol sala: fundamentos teóricos e aplicaciones prácticas. Barcelona: Paidotribo, 2003.

Recebido em: 24/08/2011

Revisado em: 28/09/2011

Aprovado em: 10/10/2011

Endereço para correspondência

wilton@pedagogiadofutsal.com.br

Wilton Carlos Santana

Universidade Estadual de Londrina, Centro de Educação Física e Desportos

Rodovia Celso Garca Cid, km 380, Campus Universitário

86055-900 - Londrina, PR - Brasil

Telefone: (43) 33714000 